\title{
Safety culture in the operating room of a public hospital in the perception of healthcare professionals ${ }^{1}$
}

\author{
Paloma Aparecida Carvalho ${ }^{2}$ \\ Leila Bernarda Donato Göttems ${ }^{3}$ \\ Maria Raquel Gomes Maia Pires ${ }^{4}$ \\ Maria Liz Cunha de Oliveira ${ }^{5}$
}

Objective: to evaluate the perception of healthcare professionals about the safety culture in the operating room of a public hospital, large-sized, according to the domains of the Safety Attitudes Questionnaire (SAQ). Method: descriptive, cross-sectional and quantitative research, with the application of the SAQ to 226 professionals. Descriptive data analysis, instrument consistency and exploratory factor analysis. Results: participants were distributed homogeneously between females (49.6\%) and males (50.4\%); mean age of 39.6 (SD \pm 9.9 ) years and length of professional experience of 9.9 ( $\mathrm{SD} \pm 9.2$ ) years. And Cronbach's $\alpha$ of 0.84 . It was identified six domains proposed in the questionnaire: stress perception (74.5) and job satisfaction (70.7) showed satisfactory results; teamwork environment (59.1) and climate of security (48.9) presented scores below the minimum recommended (75); unit's management perceptions (44.5), hospital management perceptions (34.9) and working conditions (41.9) presented the lowest averages. Conclusions: the results showed that, from the perspective of the professionals, there is weakness in the values, attitudes, skills and behaviors that determine the safety culture in a healthcare organization.

Descriptors: Patient Safety; Organizational Culture; Health Services Evaluation; Surgicenters.

\footnotetext{
${ }^{1}$ Paper extracted from master's thesis "Avaliação da cultura de segurança entre profissionais do centro cirúrgico de um hospital de porte especial: elementos para a melhoria da qualidade do cuidado aos idosos submetidos a procedimentos cirúrgicos", presented to Fundação de Ensino e Pesquisa em Ciências da Saúde, Secretaria de Estado de Saúde do Distrito Federal, Brasília, DF, Brazil.

2 MSc, RN, Hospital de Base do Distrito Federal, Secretaria de Estado de Saúde, Brasília, DF, Brazil.

${ }^{3}$ PhD, Adjunct Professor, Escola Superior de Ciências da Saúde, Fundação de Ensino e Pesquisa em Ciências da Saúde, Secretaria de Estado de Saúde, Brasília, DF, Brazil.

${ }^{4} \mathrm{PhD}$, Adjunct Professor, Faculdade de Saúde, Universidade de Brasília, Brasília, DF, Brazil.

${ }^{5}$ PhD, Adjunct Professor, Fundação de Ensino e Pesquisa em Ciências da Saúde, Secretaria de Estado de Saúde, Brasília, DF, Brazil.
}

Corresponding Author:

Paloma Aparecida Carvalho

Secretaria de Estado de Saúde do Distrito Federal

Subsecretaria de Planejamento, Regulação, Avaliação e Controle

Setor de Áreas Isoladas Norte - SAIN, Bloco B

CEP: 70086-900, Brasília, DF, Brasil

E-mail: paloma_carvalho@yahoo.com.br
Copyright $\odot 2015$ Revista Latino-Americana de Enfermagem This is an Open Access article distributed under the terms of the Creative Commons Attribution Non-Commercial License (CC BY-NC).

This license lets others distribute, remix, tweak, and build upon your work non-commercially, and although their new works must also acknowledge you and be non-commercial, they don't have to license their derivative works on the same terms. 


\section{Introduction}

The safety of the healthcare services took over an important place in public healthcare policies since the publication of the document entitled To err is human: building a safer health system, published in 1999 by the Institute of Medicine (IOM), of the United States of America (USA). Security, considered a quality dimension and recognition that healthcare services are complex systems and that healthcare can be highly damaging and lethal, sparked the search by experts and researchers for continuous improvement strategies of work processes in this area $^{(1)}$.

In Brazil, only in 2013, safety of healthcare services was the subject of the National Patient Security Programme of Ministry of Health $(\mathrm{MH})$, as well as the Resolution of Board of Directors (RDC) No. 36 of the National Health Surveillance Agency (ANVISA), which established specific guidelines and actions for patient safety in the context of the Unified Health System (SUS).

The search for quality in the healthcare services has increasingly found space in the national and international agendas and discussions on healthcare reform. It is a gradual and differentiated process that involves the reconfiguration in the relationships between professionals and patients, between demand and healthcare supply, which can be affected also by the variation in the levels of social healthcare inequality ${ }^{(2)}$.

Strategies for improving the quality of healthcare services require systematic evaluations. These go beyond the methodological debates on the purpose and utility of the evaluation in decision-making, recognition of pluralism of values and distinct points of view of the interest groups about the evaluation process(2). Thus, it is important that managers of healthcare services disseminate an evaluative culture into organizations.

Surgical centers are considered high-risk scenarios and extremely susceptible to errors. In this scenario, work processes are complex and interdisciplinary practices, with strong dependence on the individual and team performance in environments dominated by pressure and stress. Surgical complications account for a large proportion of deaths and injuries (temporary or permanent) caused by the care process, considered preventable(3).

In this regard, to know the safety culture of the environment, in which it is intended to operate, is an essential aspect to effect improvements. According to the Agency for Healthcare Research and Quality
(AHRQ), the safety culture is "the individual or collective product of values, attitudes, perceptions, competencies and behavior patterns that determine the commitment, style and competence of a healthcare organization in safety promotion"(4). In turn, the climate of security is a measurable component of the safety culture and can be assessed through the perception of professionals, since the attitudes and values are more difficult to assess ${ }^{(5)}$.

To this end, the Safety Attitudes Questionnaire (SAQ) is an instrument developed by researchers from the University of Texas (USA) that measures the climate of security perceived by the healthcare professionals. It was designed based on the Intensive Care Unit Management Attitudes Questionnaire, derived from the traditional Flight Management Attitudes Questionnaire (FMAQ), used for over 20 years by the commercial aviation, to measure the safety perception of the flight crews $^{(5)}$. The items that comprise the SAQ were highly sensitive for assessing the individual safety attitudes and exploration of the relationship between the safety environment scores and results of care provided to patients. This instrument has been used to assess the differences in the perception of proactive organizational commitment to the safety of individuals working in the operating rooms of high and medium complexity institutions in different countries. It contributes to the increase in the probability of successful implementation of resource management tools and security improvement, such as the World Health Organization Surgical Safety Checklist ${ }^{(6-8)}$.

The hospital where the study was carried out is characterized as a high complexity service in all areas, especially in surgical procedures, in the public network of the Federal District, a reference in the Central West region. It is in the process of accreditation by the Joint Commission International and in the process of implementation of several strategies to patient safety, among them is the implementation of the WHO Surgical Safety Checklist.

This hospital was included, in 2012, in the Public Hospitals Restructuring Project (RHP) of SUS Institutional Development Programme (Proadi-SUS). This action of the Ministry of Health addresses the strengthening of SUS in partnership with philanthropic hospitals of recognized quality through the training of workers and professionals, supporting to certification and accreditation processes, for the management qualification of public hospitals. 
This study was guided by the question: what is the safety culture perception among professionals working in the operating room of this hospital, according to the domains of the SAQ? The objective was to evaluate the perception of healthcare professionals about the safety culture in the operating room of a public hospital, large-sized, according to the domains of the SAQ.

\section{Method}

A cross-sectional descriptive study with a quantitative approach was carried out. It was used the Safety Attitudes Questionnaire (SAQ), with the version translated and validated to Brazil. This instrument is composed of two parts: the first part contains 41 questions on patient safety perception and the second part contains questions about the professional category, gender, age and length of professional experience ${ }^{(9)}$.

The 41 items of the SAQ are grouped into six domains: 1) Teamwork Environment (TWE): quality of the relationship and collaboration between the members of a team (items 1-6); 2); Climate of Security (CS): professionals' perception about the organizational commitment to patient safety (items 7-13); 3) Job Satisfaction (JS): positive view of the workplace (items 15-19); 4) Stress Perception (SP): recognition of the influence of stress factors in the performance of work (items 20-23); 5) Unit's Management Perception (UMP) and Hospital Management Perception (HMP), both relating to the approval of management or administrative actions (items 24-29); and 6) Working Conditions (WC): perception of the work environment quality (items 30-32). The items 14 and 34-36 are not part of any domain in the original instrument.

Each item of the SAQ follows a five-point Likert scale, organized and scored as follows: totally disagree (0 points), partially disagree (25 points), neutral (50 points), partially agree (75 points) and strongly agree (100 points ); the "not applicable" option does not score. In the final score, 0 corresponds to the worst perception of the climate of security and 100 to best perception. The calculation is made by adding the answers of the items of each domain and dividing the result by the number of items of each domain ${ }^{(9)}$, after inversion of reverse items.

The study was carried out in the Surgical Center Core (NCC) of the Federal District Base Hospital (HBDF), with a capacity of 855 beds, of which 482 are surgical beds, according to the National Healthcare Facilities Register.

The SAQ was answered by 226 professionals (sample error of 0.05) working in the reporting unit, including nurses, practical nurses, residents physicians and physicians of surgical and anesthetic areas, dentists, administrative and environmental support professionals. Inclusion criteria were: professional agreement to participate in the study and length of professional experience in the service for more than six months. Professionals away from the work activities during the collection period were excluded. Participants were recruited in their own working environment, when they were asked to respond to the instrument.

Data were collected from May to September 2013, in three shifts, by two scientific initiation students of the final year of the nursing course and two nursing residents of the surgical team of the hospital, trained by the researcher, who has extensive experience in the operating room.

It was used the Statistical Package for Social Science (SPSS), version 20.0 and Rstudio 0.98.501 software. Descriptive analysis, exploratory factor analysis and comparison between groups were carried out. The descriptive analysis of the SAQ was carried out using the mean, median and standard deviation (SD) of responses to items, calculated for each domain, ranging from 0 to 100 . Values greater than 75 mean strong agreement of the professionals on questions about patient safety. The Kaiser-Meyer-Olkin Measure (KMO) evaluates how the data adjust to the use of the factor analysis model, which resulted 0.75 , allowing the use of this analysis to data interpretation.

Along with the results of the factor analysis, there are the factor loadings that represent the covariance between the items and factors studied, which allows to identify which factor the item was linked. To estimate the factors, it was used the Component Main method, in order to reduce the scope of the data and preserve the explanation of data variability. Subsequently, it was carried out a rotation of factors to improve the interpretation of results by means of the Promax oblique rotation.

Cronbach's a coefficient was used to analyze the internal consistency of the items also called instrument reliability. The $\alpha$ value ranged from 0 to 1 , however, to prove the internal consistency, it must present a value between 0.7 and 1.0. Results below 0.7 indicate that the instrument cannot measure the construct. 
The research followed all ethical care foreseen in the Resolution 466/12 of the National Health Council. The project was approved by the Ethics Research Committee of the Foundation of Education and Health Sciences, of the State Office of Health of the Federal District (CEP/FEPECS/SES/ GDF), on $11 / 12 / 2012$, with the advice number 144.024 .

\section{Results}

The profile of participants was characterized by a homogeneous distribution among females (49.6\%) and males (50.4\%), according to Table 1. Regarding the length of professional experience, most respondents had between 1 and 2 years (26.1\%) and between 11 and 20 years (22.1\%) of experience, with a mean of 9.9 years $(S D \pm 9.2)$. Physicians are professionals with the longest length of professional experience, followed by nursing technicians. The predominant age group was between 31 and 50 years $(63.3 \%)$, with a mean of 39.6 (SD \pm 9.9$)$. Physicians were the professionals who most participated (73; 33.6\%), followed by nursing technicians $(65 ; 27.4 \%)$ and resident physicians $(51 ; 22.6 \%)$.

Table 1 - Frequency of participants regarding gender, length of professional experience, age and job title. Brasília, DF, Brazil, 2013

\begin{tabular}{|c|c|c|}
\hline Characteristic & Frequency & Percentage \\
\hline \multicolumn{3}{|l|}{ Gender } \\
\hline Male & 114 & 50.4 \\
\hline Female & 112 & 49.6 \\
\hline \multicolumn{3}{|c|}{ Length of professional experience } \\
\hline 6-11 months & 13 & 5.8 \\
\hline $1-2$ years & 59 & 26.1 \\
\hline $3-4$ years & 18 & 8.0 \\
\hline $5-10$ years & 45 & 19.9 \\
\hline $11-20$ years & 50 & 22.1 \\
\hline 21-39 years & 37 & 16.4 \\
\hline Absents & 4 & 1.8 \\
\hline \multicolumn{3}{|l|}{ Age group } \\
\hline Up to 30 years & 43 & 19.0 \\
\hline $31-40$ years & 79 & 35.0 \\
\hline $41-50$ years & 64 & 28.3 \\
\hline $51-60$ years & 27 & 11.9 \\
\hline Over 60 years & 4 & 1.8 \\
\hline Absents & 9 & 4.0 \\
\hline \multicolumn{3}{|l|}{ Profession/occupation } \\
\hline Administrative & 5 & 2.2 \\
\hline
\end{tabular}

(continue...)
Table 1 - (continuation)

\begin{tabular}{lcc}
\hline \multicolumn{1}{c}{ Characteristic } & Frequency & Percentage \\
\hline Nurse & 13 & 5.8 \\
Physician & 73 & 32.3 \\
Resident Physician & 51 & 22.6 \\
Dentist & 11 & 4.9 \\
Environmental support & 8 & 3.5 \\
Nursing technician & 65 & 28.8 \\
Total & 226 & 100.0 \\
\hline
\end{tabular}

The total score of the SAQ, in the investigated unit, ranged from 34.5 to 74.9 , per domain, with mean of 53.5 $(\mathrm{SD} \pm 13.9)$ and median of 52.4 (Table 2). The domains of job satisfaction (0.76), stress perception (0.74) and hospital management perception (0.77) had significant internal consistency, with a value higher than 0.7 and, therefore, ensuring the reliability of the construct. However, the domains of teamwork environment (0.40), climate of security $(0.50)$, unit's management perception (0.63) and working conditions (0.58) showed $\alpha$ value less than 0.7 , indicating low correlation amongst the items.

The scores also varied per occupational category, and resident physicians presented the lowest mean (50.4), followed by nurses (51.1) and physicians (51.6). The highest averages were achieved by the administrative (74.6), followed by the environmental support (62.9) (Table 3).

Table 2 - Descriptive analysis and Cronbach's $\alpha$, per domain, of the Safety Attitudes Questionnaire, Brasília, DF, Brazil, 2013

\begin{tabular}{lcccc}
\hline \multicolumn{1}{c}{ Domains } & Cronbach's $\boldsymbol{\alpha}$ & Mean & Median & $\begin{array}{c}\text { Standard } \\
\text { Deviation }\end{array}$ \\
\hline $\begin{array}{l}\text { Teamwork } \\
\text { environment }\end{array}$ & 0.40 & 59.1 & 58 & 18.5 \\
$\begin{array}{l}\text { Climate of } \\
\text { Security }\end{array}$ & 0.50 & 48.9 & 50 & 19.6 \\
$\begin{array}{l}\text { Job } \\
\text { satisfaction }\end{array}$ & 0.76 & 70.6 & 75 & 22.0 \\
$\begin{array}{l}\text { Stress } \\
\text { Perception }\end{array}$ & 0.74 & 74.9 & 81 & 25.6 \\
$\begin{array}{l}\text { Unit's } \\
\text { management } \\
\text { perception }\end{array}$ & 0.63 & 44.5 & 46 & 21.6 \\
$\begin{array}{l}\text { Hospital } \\
\text { management } \\
\text { perception }\end{array}$ & 0.77 & 34.5 & 33 & 22.3 \\
$\begin{array}{l}\text { Work } \\
\text { conditions }\end{array}$ & 0.58 & 41.9 & 41 & 25.9 \\
\begin{tabular}{l} 
Total \\
\hline
\end{tabular} & 0.84 & 53.5 & 52.4 & 13.9 \\
\hline
\end{tabular}


Table 3 - Score of the perceptions of professionals of the operating room, per job title, according to the domains and total of the Security Attitudes Questionnaire. Brasília, DF, Brazil, 2013

\begin{tabular}{|c|c|c|c|c|c|c|c|c|}
\hline Job Title & TWE$^{*}$ & $\mathrm{CS}^{\dagger}$ & JS $^{\ddagger}$ & SP§ & UMP\| & HMPף & $W^{* *}$ & Total \\
\hline Administrative & 82.5 & 66.7 & 94 & 64.1 & 77.6 & 55 & 77.5 & 74.6 \\
\hline Nurses & 59 & 49.2 & 77.7 & 68.7 & 63.4 & 46.9 & 22.9 & 51.1 \\
\hline Physicians & 58.8 & 44.5 & 63.7 & 77.9 & 41.4 & 33 & 41.3 & 51.6 \\
\hline Resident physicians & 56.3 & 48.1 & 64.8 & 79.3 & 37.4 & 28.7 & 38 & 50.4 \\
\hline Dentists & 56.5 & 45.2 & 67.7 & 68.5 & 46.2 & 35.6 & 44.7 & 52.1 \\
\hline Nursing technicians & 66.8 & 47.5 & 89.3 & 70.8 & 65.5 & 54 & 46.3 & 55.9 \\
\hline Environmental support & 59.5 & 54 & 78 & 71.2 & 46.1 & 36.9 & 45.5 & 62.9 \\
\hline Total & 59.1 & 48.9 & 70.6 & 74.8 & 44.5 & 34.4 & 41.9 & 53.5 \\
\hline
\end{tabular}

* Teamwork environment

+ Climate of security

₹ Job satisfaction

$\S$ Stress perception

II Unit's management perception

ๆ Hospital management perception

** Work conditions

\section{Discussion}

Participants were distributed homogeneously among females (49.6\%) and males (50.4\%). Females predominated among the nursing professionals, while males predominated amongst physicians. The participation of physicians (32.3\%), combined or not with participation of resident physicians $(22.6 \%)$ reveals a singular characteristic of this research. In studies with the application of the SAQ, the proportion of physicians is lower compared to other healthcare team members ${ }^{(10-11)}$.

Regarding the length of professional experience, it was observed that professionals with over 5 years of experience account for over $60 \%$ of participants, due to the type of employment contract of the professionals with the institution, which is a statutory contract. The job stability of the professionals may contribute to changes in the labor process, since the institution does not suffer the consequences of high personal replacement rates (turnover).

A study carried out in US healthcare services showed that working conditions are associated with injuries in patients and nurses. The registration of nursing hours per patient/day showed a negative association with the falls and pressure ulcers. On the other hand, the increased turnover of the staff in the unit has increased the risk of injury in nurses, while its decrease has reduced the chances of patient falls ${ }^{(12)}$.

The SAQ, in the assessed scenario, presented Cronbach's $\alpha$ of 0.84 , similar to that found in the instrument translation study for Brazil $(a=0.89)$. This value suggests that the instrument is suitable for measuring the proposed construct. However, in the analysis per domain, it was observed that Cronbach's a ranged from 0.4 to 0.7 . The TWE (0.4), CS (0.5) and JS (0.5) domains showed a values far below the recommended $(0.7)$, indicating low correlation between the items of these domains. This result indicates the need for instrument application in other samples, for greater reliability and validity of the instrument.

In a research carried out in Taiwan, the Cronbach's a ranged from 0.79 to TWE, 0.81 to $\mathrm{CS}, 0.91$ to JS, 0.87 to the management perception, and 0.78 to $\mathrm{WC}^{(13)}$. In Australia(14), Cronbach's $\alpha$ ranged from 0.65 to 0.81 , and in Norway ${ }^{(11)}$, the Cronbach's $\alpha$ ranged from 0.68 to 0.85 , for the six domains that compose the instrument.

Research has shown that item/total correlations between the domains were considered from moderate to strong, with the exception of the SP domain(13). This domain has been poorly correlated with other domains of the SAQ, thereby, some researchers ${ }^{(15)}$ suggest that this subscale should be omitted from the overall calculation of the instrument and analyzed separately. However, moderate correlations of this domain with the other domains and the total SAQ were found in the assessment of this healthcare unit.

The total score of the SAQ ranged from 34.4 to 74.8, per domain, with average of 53.5. The average score shows that the perception of the safety culture among professionals is below international recommendations, which is 75 for a good perception of safety culture. Some research using this instrument in the national and international contexts, suggest that scores above 80 indicate a strong consensus among professionals on the safety environment. However, those below 60 
represent a warning sign for the institutions, since they indicate the need for actions for implementing the safety culture $^{(6,13)}$. It is worth mentioning that a study carried out in six public hospitals, in three regions of Brazil, with 1301 professionals of medical and surgical wards, had an average of $61.5^{(13)}$.

The perception of the professionals about the safety culture varied in relation to the assessed domains. The teamwork environment presented an average of 59.1 , with a mean of $58.3(S D=18.5)$, a reasonable result when compared to the international literature. Research carried out in Taiwan showed an average of $48.9 \%$ of positive attitudes regarding the teamwork

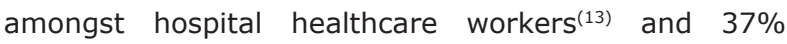
amongst respiratory therapists ${ }^{(16)}$. However, in Greece, in 2011, it was found a score of 74.1 for this domain ${ }^{(17)}$. A coordinated team, with good communication and working cooperatively, yields a more humanized care and avoid discontinuity and high-risk situations for the patient.

Regarding the climate of security the average was 48.9 (SD \pm 19.6$)$. In Brazil, it was found an average of $69.4^{(9)}$, while other studies using the same instrument in Ireland $^{(18)}$ and in the United States of America(19) ${ }^{(19}$ showed results ranging from 65.9 to 79.7 , respectively. In Taiwan it was found an average of 21 for this domain ${ }^{(16)}$. The results of the NCC reveal a need for initiatives to promote patient safety in this environment.

The job satisfaction domain (mean=70.6, $\mathrm{SD} \pm 22.5$ ) showed the second most favorable outcome amongst NCC professionals, which is consistent with the findings of another study, conducted in Brazilian hospitals (mean=77.6, SD \pm 27.8$)^{(13)}$. By comparing with international studies ${ }^{(16-17,19)}$, it is observed that in Brazil the professionals are more satisfied with their work. This is a quite favorably result, since the job satisfaction directly influences the safety culture and is related to fewer adverse events(17).

The stress perception (mean 74.8; $\mathrm{SD} \pm 25.64$ ) is slightly below the recommended, which is 75 . However, this domain was the one showing the best perception by the professionals of the NCC. In the USA, a study assessing the differences in the perceptions on patient safety amongst professions revealed that stress recognition and working conditions differ according to the profile of caregivers and professionals. Anesthesiologists had more favorable stress perception (mean=82) than nurses (mean=69) and surgeons (mean=65). In the operating room, the perceptions about working conditions were less favorable among nurses (mean=57) than among surgeons (mean $=75)^{(19)}$. A research carried out in Tehran, before and after a training course on safety culture, in a teaching hospital, showed low stress perception by the managers, with average ranging from 20.9 to $27.3^{(20)}$.

The UMP (mean=44.5, SD \pm 21.6$)$ and HMP (mean=34.4, $S D \pm 22.3$ ) domains, related to the management of the unit and the hospital, achieved the lowest scores among all domains of the SAQ, followed by working conditions (mean=41.9, SD \pm 25.9 ). Low scores regarding the perception of professionals about hospital management indicate barriers between the nursing staff and the hierarchical superiors with respect to the dialogue on patient safety issues ${ }^{(21)}$. In the study carried out to characterize the safety culture perceptions, in a national sample of agencies of Emergency Medical Services (EMS) in the USA and Canada, it was observed a wide variation in the management perception (mean=67.2), suggesting that this domain oscillates according to the prevailing management model in the assessed scenario(22).

In relation to the working conditions, studies carried out in Taiwan and Tehran obtained scores of 31.8 and 59.1, respectively, among hospital workers ${ }^{(13,16,20)}$, both considered low. In Tehran, this domain achieved a higher score, after a process of education, increasing the average from 59.1 to $84.5^{(20)}$.

Low perception in relation to the unit's management, hospital management and working conditions suggests that professionals working in healthcare do not notice any commitment from the institution's management with the latent factors of safety culture. It also indicates the need for interventions to change this culture, such as continuing education processes. The SAQ results showed that HMP and UMP domains presented low correlation between the items that comprise them.

Healthcare organizations are highly complex systems, and therefore, need to implement a management model focused on patient safety. Studies suggest that SAQ results may provide a useful starting point by assessing the safety culture, because they serve as a criterion to guide the needs and opportunities for quality improvement and patient safety ${ }^{(23)}$.

Systematic monitoring of safety culture can contribute to promoting teamwork and safe care throughout the patient's stay in the service. It is emphasized that, the interpretation and analysis of results are essential, as the average score of the SAQ demonstrates that all domains are equally important and that poor performance in one domain (climate of 
security) can be compensated by a good performance in other domain (job satisfaction) ${ }^{(23)}$.

In high reliability organizations, such as commercial aviation and nuclear energy, climate of safety is a proactive measure, which supplements traditional retrospective metrics such as number of deaths and accidents ${ }^{(24)}$. In this sense, measurement of the climate of safety among healthcare professionals supplements the retrospective metrics related to patient safety, such as the number of adverse events, allowing the recognition of the system's weaknesses, as well as the dimensions in which the service needs to invest more intensely. The development of an organizational culture that prioritizes safety is critical to the consolidation of strategies to improve the quality of the patient safety ${ }^{(25)}$.

\section{Conclusion}

The results of this study demonstrate, in the perspective of the professionals, weakness in the values, attitudes, skills, competencies and behaviors that determine the safety culture in a healthcare organization. It was observed a detachment from the hospital management and the unit management, in relation to professionals, poor working conditions and negative safety culture. Consistent interventions in these aspects are suggested to provide a safe environment for both professionals and patients. These results may be useful for the managers in the area, since they point out directions and alternatives for promoting patient safety, such as communication among their teams and introduction of new tools, such as the WHO Surgical Safety Checklist.

The limitations of this study include the use of perceptions rather than personal behavior and lack of use of assistance results. It is suggested that followup surveys on safety culture are used to assess the progress in the implementation of processes to improve the surgical care and patient safety, as well as studies on adverse events and incidents.

\section{Acknowledgements}

To the professionals who participated in this study.

\section{References}

1. Kohn LT, Corrigan JM, Donaldson MC, editors. To Err is Human: building a safer health system. Washington
(DC): Committee on Quality of Health Care, Institute of Medicine, National Academy Press; 2000.

2. Serapioni M. Avaliação da qualidade em saúde. Reflexões teórico-metodológicas para uma abordagem multidimensional. Rev Crít Ciênc Soc. 2009;85:65-82.

3. Leape LL, Brennan TA, Laird N, Lawthers AG, Russell Localio A, Barnes BA, et al. The nature of adverse events in hospitalized patients-results of the Harvard Medical Practice Study II. N Engl J Med. 1991;324:377-84.

4. Sammer CE, Lykens K, Singh KP, Mains D, Lackan NA. What is patient safety culture? A review of the literature. J Nurs Scholarsh. 2010;42(2):156-65.

5. Sexton J, Helmreich R, Neilands T, Rowan K, Vella K, Boyden J, et al. The Safety Attitudes Questionnaire: psychometric properties, benchmarking data, and emerging research. BMC Health Serv Res. 2006;6(44):1-10.

6. Carney BT, West P, Neily J, Mills PD, Bagian JP. Changing Perceptions of Safety Climate in the Operating Room With the Veterans Health Administration Medical Team Training Program. Am J Med Qual. 2011;26(3):181-4.

7. Carney BT, West P, Neily J, Mills PD, Bagian JP. Differences in Nurse and Surgeon Perceptions of Teamwork: Implications for Use of a Briefing Checklist in the OR. AORN J. 2010;91:722-9.

8. Bleakley A, Allard J, Hobbs A. Towards culture change in the operating theatre: Embedding a complex educational intervention to improve teamwork climate. Med Teach. 2012;34:e635-e40.

9. Carvalho REFL, Cassiani SHB. Questionário Atitudes de Segurança: Adaptação transcultural do Safety Attitudes Questionnaire - Short Form 2006 para o Brasil. Rev. Latino-Am. Enfermagem 2012;20(3):575-82.

10. Deilkås E, Hofoss D. Patient safety culture lives in departments and wards: Multilevel partitioning of variance in patient safety culture. BMC Health Serv Res. 2010;10:85.

11. Deilkas E, Hofoss D. Psychometric properties of the Norwegian version of the Safety Attitudes Questionnaire (SAQ), Generic version (Short Form 2006). BMC Health Serv Res. 2008; 8:191.

12. Taylor JA, Dominici F, Agnew J, Gerwin D, Morlock $L$, Miller MR. Do nurse and patient injuries share common antecedents? An analysis of associations with safety climate and working conditions. BMJ Qual Saf. 2012;21(2):101-11.

13. Lee WC, Wung HY, Liao HH, Lo CM, Chang FL, Wang PC, et al. Hospital safety culture in Taiwan: a nationwide survey using Chinese version safety attitude questionnaire. BMC Health Serv Res. $2010 ; 10: 234$. 
14. Chaboyer W, Di Chamberlain, Hewson-Conroy K, Grealy B, Elderkin T, Brittin M, et al. Safety culture in Australian Intensive Care Units: establishing a baseline for quality improvement. Am J Crit Care. 2013;22:93102.

15. Taylor JA, Pandian R. A dissonant scale: stress recognition in the SAQ. BMC Res Notes. 2013;6:302.

16. Shie HG, Lee WC, Hsiao HF, Lin HL, Yang LL, Jung F. Patient Safety attitudes among respiratory therapists in Taiwan. Respir Care. Dec. 2011;56(12):1924-9.

17. Raftopoulos V, Pavlakis A. Safety climate in 5 intensive care units: a nationwide hospital survey using the Greek-Cypriot version of the Safety Attitudes Questionnaire. J Crit Care. 2013 Feb;28(1):51-61.

18. Relihan E, Glynn S, Daly D, Silke B, Ryder S. Measuring and benchmarking safety culture: application of the safety attitudes questionnaire to an acute medical admissions unit. Ir J Med Sci. 2009;178:433-9.

19. Taylor J. Utility of patient safety case finding methods and associations among organizational safety climate, nurse injuries, and errors. Baltimore (MD): Johns Hopkins University; 2008.

20. Azimi L, Bahadori M. The effect of Safety Culture Education on Improvement of Managers' Attitudes towards Patients' Safety. Int J Collab Res Intern Med Public Health. 2012;4(3):217-26.

21. Rigobello MCG, Carvalho REFL, Cassiani SHB, Galon T, Capucho HC, Deus NN. Clima de segurança do paciente: percepção dos profissionais de enfermagem. Acta Paul Enferm. 2012;25(5):728-35.

22. Patterson PD, Huang DT, Fairbanks RJ, Simeone $S$, Weaver M, Wang HE. Variation in emergency medical services workplace safety culture. Prehosp Emerg Care. 2010;14(4): 448-60.

23. Profit J, Etchegaray J, Petersen LA, Sexton JB, Hysong SJ, Mei M, et al. The Safety Attitudes Questionnaire as a tool for benchmarking safety culture in the NICU. Arch Dis Child Fetal Neonat Ed. 2012;97:127-32.

24. Frankel A, Grillo SP, Pittman M, Thomas EJ, Horowitz $L$, Page $M$, et al. Revealing and resolving patient safety defects: The impact fo leadership walkrounds on frontline caregiver assessments of paciente safety. Health Serv Res. 2008;43(6):2050-66.

25. Speroff T, Nwosu S, Greevy R, Weinger MB, Talbot $T R$, Wall RJ, et al. Organizational culture: variation across hospitals and connection to patient safety climate. Qual Saf Health Care. 2010;19:592-6. 